\title{
Engineering design and manufacturing infrastructure availability and supply in Ghana
}

\author{
Akpakpavi Michael \\ Department of Mechanical Engineering, Accra Polytechnic, Accra, Ghana
}

Email address:

micakpakpavi@yahoo.com

To cite this article:

Akpakpavi Michael. Engineering Design and Manufacturing Infrastructure Availability and Supply in Ghana. International Journal of Materials Science and Applications. Vol. 3, No. 5, 2014, pp. 210-216. doi: 10.11648/j.ijmsa.20140305.22

\begin{abstract}
The purpose of this paper is to assess the availability and supply of mechanical engineering design and manufacturing infrastructure in Ghana. In the study, the availability of engineering inputs were investigated using a questionnaire administered on suppliers/dealers in engineering inputs, local engineering materials producers as well as machinery design and manufacturing firms in the country. In addition, some amount of data was generated through personal observation. The survey revealed that most of the engineering materials and components available in the country are brought from outside sources as new or used inputs in various forms and sizes; however their quality and specifications are not known. It further revealed that, majority of the suppliers/dealers have very low technical qualifications with a large number of them having no background at all in relevant technical areas. To enhance the supply of machinery infrastructure in the country, government as well as the banks must assist the local industries to produce more of the inputs locally. The Ghana Institution of Engineers and the Ghana Standards Board should regularly organize in-service training for the suppliers/dealers in the country to enable them enhance their competencies and engineering literacy levels.
\end{abstract}

Keywords: Ghana, Manufacturing, Infrastructure, Availability, Suppliers

\section{Introduction}

\subsection{Background to the Problem}

Manufacturing industry creates wealth for the people of a nation. Developed countries such as the United States of America, Germany, Japan and others have achieved success principally because they are able to add value to bulk of natural raw material using machinery they design and manufacture. Poor countries export raw materials such cocoa, iron, ore, and raw diamonds. Rich countries export, often to those same poor countries, more complex products such as chocolate, cars and jewels. If poor countries want to get rich, they should stop exporting their resources in raw form and concentrate on adding value to them. Otherwise, rich countries will get the lion's share of the value and all of the good jobs [1].

Ghana has since independence tried to industrialized, but to date, has made modest progress in this direction. Several factors account for this, and notable among them is a lack of a well-developed raw material and component supply infrastructure to support professional engineering design and manufacture. An industrial survey of standard raw material and component parts used in design and manufacturing in Ghana could help bring to light the extent of availability, affordability, quality and state of those inputs.

\subsection{Problem Statement}

Ghana for example, has been endowed with such raw materials as cocoa, timber, cotton, gold, diamond, and so on [2]. To date, Ghana has not been able to locally add value to most of these raw materials because the engineering capital goods design and manufacturing sector is not well developed. These materials are exported mostly in their raw states and thus earn far less foreign exchange than is possible if value were added to them before export. Currently, in Ghana, a sizeable proportion of the inputs required to support mechanical engineering design and manufacturing are brought from external sources by mostly non-engineering importers, and sometimes by engineering manufacturing firms themselves. It is thought that large amounts of used inputs are brought into the country because the prices of new materials and components are too expensive. This situation, where many engineering 
manufacturing firms resort to large scale usage of scrap units whose properties are generally not tested, tends to undermine the quality of the products produced from these. Not surprisingly, these products often fail to meet international standards.

It is in view of the above challenges facing engineering design and manufacturing in Ghana that the study is conducted. The goal of this paper is to come out with appropriate recommendations to help improve the standard of machinery design and manufacturing in the country.

\subsection{Justification}

The success of any design and manufacturing ente- rprise hinges on uninterrupted availability of right raw materials and components inputs. This paper provides information about a wide range of metal and other raw material and standard parts used generally for design and manufacturing activities. It also provides useful information about the range of sizes as well as the condition of the mechanical units, components and materials available in the country for stated purposes. Based on these, recommendations are made to the appropriate authorities to come up with policies that will help improve on engineering materials and components supply infrastructure. When this is achieved, more design and manufacturing industries will be in a position to function optimally with the result that the efficiency and effectiveness of engineering design and manufacturing in the country will be greatly improved.

\subsection{Aims and Objectives}

The primary aim of the study is to investigate the availability of raw material and component supply infrastructure in Ghana to support professional engineering design and ma- nufacturing. To achieve this, the following specific objective will be used as sign posts.

1. To find out the range of mechanical engineering units, co- mponents and raw materials currently available, as well as those not available in the country for machinery design and manufacturing.

2. To determine the range of sizes, ratings, as well as the st- ate of those inputs available in the country.g

3. To investigate the criteria and decision processes used by importers in importing those engineering materials and components into country.

4. To examine the technical qualification, the general termi- nology as well as the engineering language literacy level of

5. the local importers and dealers.

6. To assess the amount of engineering inputs produced loc- ally as compared to those imported into the country.

7. To verify, finally, the effect of non-availability of required materials inputs on overall engineering design and manufac- turing efficiency and effectiveness in the country.

\section{Materials and Methods}

\subsection{Materials}

Two different types of survey were used to gather data: structured questionnaires and face-to-face interviews. The questionnaires were administered to selected engineering materials and components suppliers (importers), machinery designers and manufacturers as well as engineering material producers in Kumasi, Accra and Tema metropolis. The survey was confined to these places because most industrial activities are concentrated there [3]. Indeed, this finding is still the same now [4]. Also, the three centers mentioned are all urban areas. Hence, it was taught that the views of the respondents from these centers would adequately represent the whole population.

\subsection{Methods}

The target group could be divided into several cate- gories such as engineering materials and components dealers and machinery manufacturers. Owing to this, Stratified Random Sampling was used in selecting the samples. The designed questionnaires were administered in a survey that involved visit to these companies. Eight (8), fifteen (15) and ten (10) of the questionnaires were administered to the targeted local mechanical engineering raw materials and components suppliers/dealers in Kumasi, Accra, and Tema respectively. However, twelve (12), thirteen (13) and nine (9) separate questionnaires were administered to the machinery designers and manufacturers at those same locations mentioned respectively. Three local engineering material producers all located in Tema were also identified and served with separate questionnaires, but only two (2) of them responded. The remainder could not respond to the questionnaire since they were no more producing engineering materials of any sort. In all, the response rate of the questionnaires was greater than $70 \%$. Apart from questionnaires been the main research instrument used, observations, and discussions were also used to some extent in gathering the relevant data. Where appropriate, the data collected was analyzed using bar and pie charts and the results were summarized with appropriate conclusions and recommendations made from it. The associated issues are as presented below.

\section{Results}

\subsection{Areas and Level of Technical Training}

On the issue of technical training area, out of the $70 \%$ response rate, about $8 \%$ of the suppliers/dealers have had technical training in Mechanical Engineering, 52\% have had training in Marketing, 24\% had training in Purchasing and Supply, while 16\% trained in Business Administration. None have had training in such technical areas as Electrical Engineering, Materials Engineering and Agricultural Engineering. Moreover, out of the $70 \%$ response rate, about $60 \%$ of the machinery manufacturers have had formal training in Mechanical Engineering, 12\% had training in 
Agricultural Engineering whiles 28\% had informal training in other fields such as Welding and Fabrication and Basic Physics. The responses given by the suppliers/dealers and machinery designers and manufacturers are as shown in fig. land 2 .

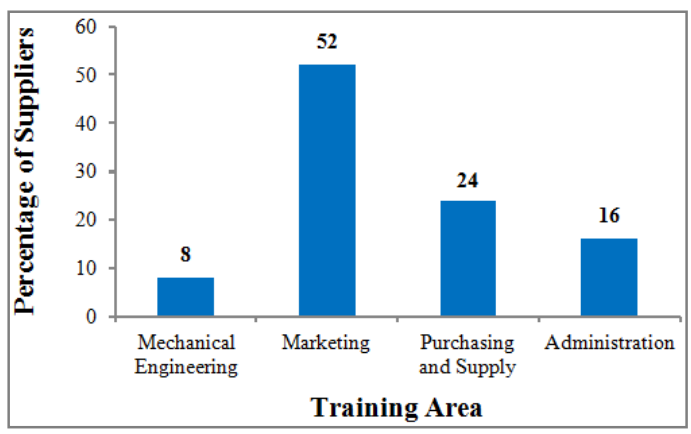

Figure 1. Technical training areas of suppliers/dealers

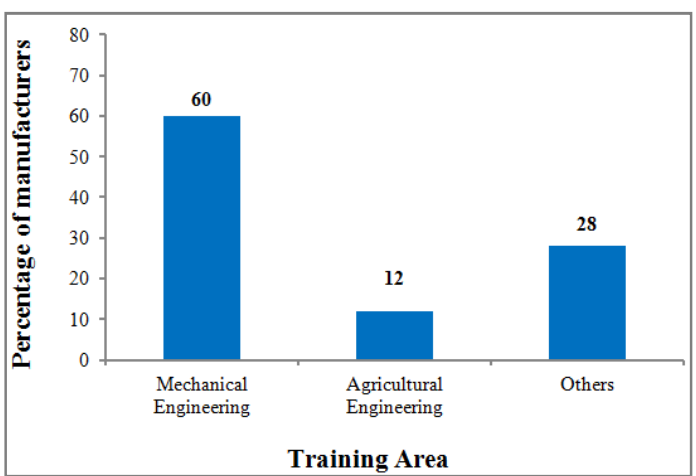

Figure 2. Technical training areas of machinery designers and manufacturers

With regard to the level of training, $12 \%$ of the suppliers/dealers had university degree, $20 \%$ have had diploma, $12 \%$ had intermediate/advanced certificates whilst $56 \%$ had other qualifications such as G.C.E 'O' and ' $A$ ' levels, SSSCE, BECE and Middle School Leaving Certificates.

The responses given by the machinery designers and manufacturers on the same issue of level of training also show that $16 \%$ have had university degree, $24 \%$ had diploma, $40 \%$ have had intermediate/Advance certificates while $20 \%$ possessed other qualifications essentially in the form of apprenticeship. Fig. 3 and 4 pictures these responses.

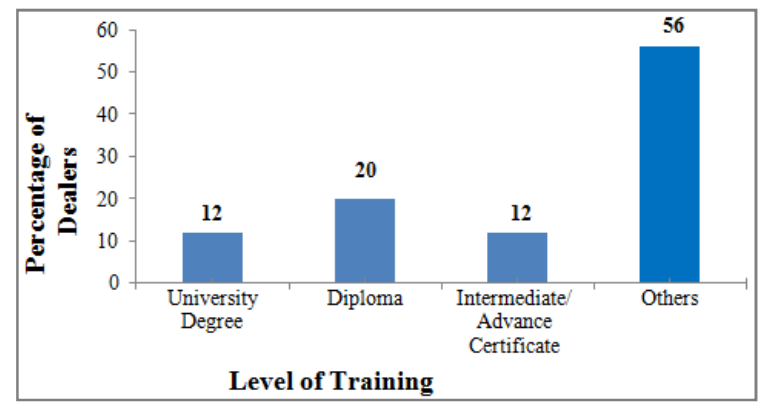

Figure 3. The level of technical training areas of suppliers/dealers

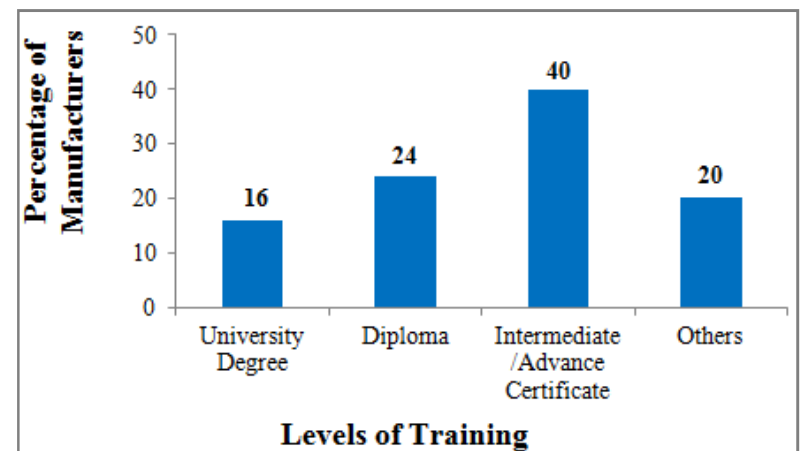

Figure 4. The level of technical training areas of machinery designers and manufacturers

\subsection{Engineering Materials and Components Dealt in by Suppliers}

Almost all of the suppliers/dealers imported and supplied the following engineering materials and components to machinery designers and manufacturers and therefore made them available in the country. These include: steel sheets/plates, long steel plates, steel flat bars, steel square pipes/bars, steel rectangular pipes, steel round pipes/bars, hexagonal steel bars, stainless steel sheets/plates/pipes/bars, seamless steel pipes, galvanized plates, steel angle bars, Uchannels, I\&H beam steels, brass round short bars, bronze round short bars, brass hexagonal bars, and copper round short bars.

Engineering components available include: bearings, bearing mountings, chains, belts, sprockets, pulleys, couplings, springs, gearboxes, reduction units, washers, pins, retaining rings, ' $O$ ' rings, bushes, some types of motors, switches and fuses.

\subsection{Customers Placing Request Using Full Technical Specifications}

On the issue of how often customers place request using full technical specifications. About 4\% did it 'frequently', $12 \%$ 'sometimes' did it, $8 \%$ 'occasionally' did it whilst $76 \%$, 'never' placed request using full technical specifications (example, $0.25 \%$ carbon steel). Fig. 5 depicts this finding in percentage terms.

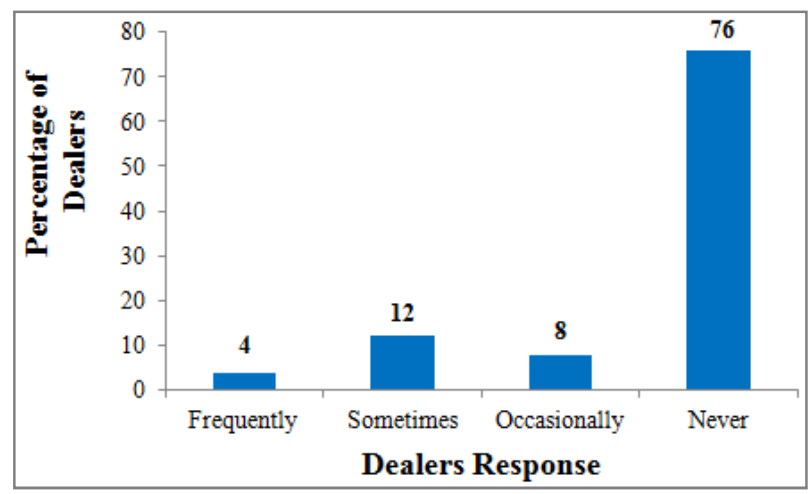

Figure 5. Extent of placing order using full technical specifications 


\subsection{Provision of Products Catalogue/Full Technical Data}

On the issue of whether the suppliers provide products catalogue to customers, as illustrated in fig. 6 , only about $8 \%$ did it whilst the remaining $92 \%$ did not offer products catalogue to their customers.

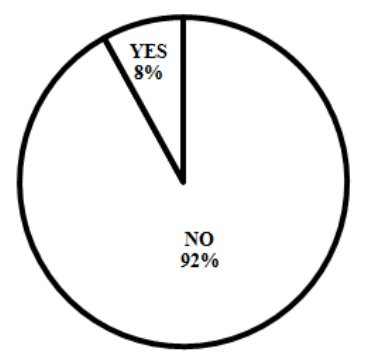

Figure 6. Extent of practice of providing product catalogue to customers

\subsection{Interactions with Machinery Manufacturers to Know Their Needs}

On the question of how frequently suppliers interact with machinery manufacturers to know their needs, about only $4 \%$ did it 'Often', $8 \%$ did it 'sometimes', $12 \%$ had done it 'occasionally', whilst $76 \%$ had 'never' interacted with the machinery manufacturers. Fig. 7 shows this finding.

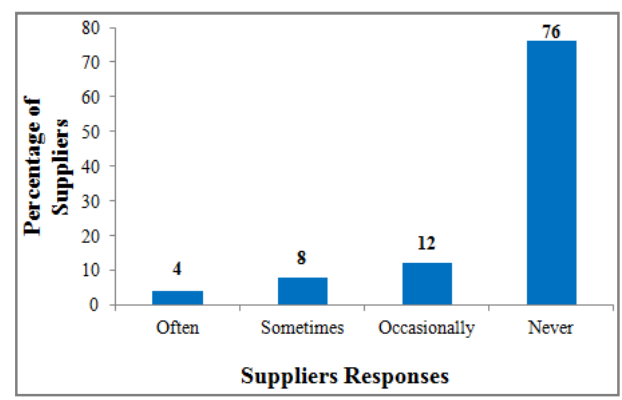

Figure 7. frequency of interaction of suppliers with machinery manufacturers

\subsection{Inputs Obtainable on the Local Market for the Design and Manufacture of Machinery and other Engineering Products}

On the issue of inputs obtainable on the local market for machinery design and manufacturing, $80 \%$ of the machinery manufacturers did obtain all their inputs on the local market whilst the remainder, $20 \%$, did not obtain all their inputs locally. Fig. 8 depicts this finding.

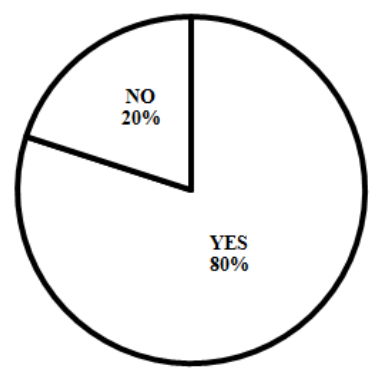

Figure 8. Proportions of firms able to obtain all their inputs locally

\subsection{Percentage of Inputs Made Up of Substitutes}

On the above issue, about $80 \%$ of the engineering machinery designers always used between $50 \%$ to $100 \%$ 'substitute' engineering inputs in their manufacturing activities. About $12 \%$ had always used between $1 \%$ to $49 \%$ 'substitutes', whilst about $8 \%$ always used under $1 \%$ 'substitute' engineering materials and components in the manufacture of their machinery and other engineering products.

\subsection{Effects of Non-Availability of Required inputs on Overall Design and Manufacturing Activities}

On the issue of the effects of non-availability of required engineering inputs, almost all of the machinery design and manufacturers experienced delays in their manufacturing activities.

\section{Discussion}

\subsection{Areas and Level of Technical Training}

In developed countries as well as some developing countries, dealership in engineering materials and components are exclusively reserve for individuals who have had formal training in engineering materials and components [5]. These trained engineers are made to form societies and produce engineering materials and components based on approved standards and codes [6]. Engineers are expected to exhibit standards of honesty, and integrity. Engineering has a direct and vital impact on the quality of life for all people. Accordingly, the services provided by engineers among other things require protection of public health, safety, and welfare [7].

Unfortunately, this is not the situation in the country. As shown in figure three of this paper, most of the engineering suppliers/dealers in the country possess little or no formal education in the relevant technical areas. They therefore have difficulties in stating the composition as well as the quality level of the engineering inputs they import into the country (for example, $0.2 \%$ carbon steel). The Ghana Standards Board is also not in a position to do same, due to lack of requisite logistics. Again, as indicated in fig. 4 above, a large majority of the machinery design and manufacturers in the country possess low technical qualifications. The high level of illiteracy suggests the difficulties the manufacturers face in specify the quality and composition of the engineering inputs they require for their manufacturing activities. Undoubtedly, this is a major setback in Ghana's quest to improve and enhance the engineering design and manufacturing sector.

\subsection{Importation of Supplies upon Request by Customers}

As indicated in fig.5 of this paper, a large number of customers place requests for engineering inputs without using full technical specifications. Moreover, an informal interaction with the suppliers/dealers reveals that, the 
requests made sometimes by the customers coupled with the suppliers' own personal experiences in the import business forms the basis upon which the suppliers import those engineering inputs into the country. A lot of research takes place continually on daily basis to improve the available engineering inputs to match the ever changing and increasing trends in technology in most developing as well as developed countries [8].

None of the engineering materials and components suppliers/dealers as well as the local engineering material pro- ducers surveyed indicate any intentions of introducing new stock of engineering materials and components in the near foreseeable future. Undoubtedly, this means that, significant improvements in engineering inputs supply in the country to match the current technological trends may take a very long time to achieve.

\subsection{Provision of Product Catalogues/Full Technical Data}

As a common practice in most technological advanced countries, almost all engineering products, materials, components etc. are supplied together with catalogues usually containing full technical data [9]. This enables potential buyers and customers to be aware, not only of the prices of those items, but more importantly, the range of sizes, quality, compositions, properties and state of those products. A good supplier will generally provide as much information as needed for the engineer to reach a functional, cost-effective and deliverable solution to the design challenge in materials. An engineer who calls a supplier with a predetermined material wants to conduct a quick review of the specifications to be certain of that materials viability in application [10].

As illustrated in fig. 6, a large majority of suppliers/dealers do not offer products catalogue to their customers. Also, none of the two engineering material producing firms follows this practice, which is common in most advanced countries. The worst offenders are those that deal in important critical engineering components such as pulleys, speed reducers, transmission chains, bushes, sprockets, and some types of motors. A large percentage of the components cannot be obtained in the country as 'new' components and therefore are only available as second hand inputs in scrap yards. Thus, virtually no technical data accompanies such products. This in turn, makes it difficult for machinery manufacturers to be informed regarding the technical characteristics of those components.

\subsection{Engineering Products Inputs Obtainable On the Local Market}

As depicted in figure eight of this paper, a good number of the engineering design and manufacturing firms in the country claimed they are able to obtain all their inputs on the local market for their manufacturing activities. However, experienced personnel are required to assist to re-evaluate final materials and manufacturing sequences to assure full compliance with the needs of a product [14]. In technologically advanced countries such as the USA, Germany and the rest, specialist material engineers are responsible for materials testing, maintaining inventories and ordering supplies [15]. From observation, large majority of the local ma- chinery manufacturers do not give due consideration to the composition as well as the state of those engineering inputs they use in their machinery fabrications, a key requirement for acceptable products. Hence, they can hardly establish the quality, suitability and acceptability of those engineering inputs.

On the contrary, a minority (20\%) of manufacturers, who seem qualified and highly trained, tend to do proper assessment of the available engineering inputs before using them. They seem to have come to terms with the fact that they are not able to obtain all their engineering inputs from the local market, and, as such have identified the nonavailable engineering inputs. These include high carbon steel products, most non-ferrous metals as well as critical components such as new gearboxes, couplings, bushes, some types of motors etc.

\subsection{Effects of Non-Availability of Required Inputs}

The required types, sizes, quality, state and composition of most engineering materials and components are readily available and can be obtained in the hardware shops of most advanced countries for machinery design and manufacturing [17].

An informal discussion with majority of the manufacturers reveals that, they spend a lot of their time moving from one scrap yard to another in search of the required engineering inputs. Sometimes, those manufacturers located in Kumasi and its environs are forced to travel a long way to Accra and Tema for a number of weeks to enable them obtain the needed engineering inputs. According to them, they sometimes have to wait for months for new consignments of engineering inputs to be brought into the country by importers.

Avery disturbing situation was witnessed by the researcher at 'Homeku Engineering Limited', a machinery manufacturing firm located in 'Ashiaman', a suburb of Accra. The firm was to supply one hundred pieces of palm oil expeller machines as part of a World Bank project. Gearboxes (speed reducers) and other critical engineering components were required to be used in the manufacture of those machines. Unfortunately, however, the firm was not able to obtain the required types, sizes, as well as the number of speed reducers needed from any of the renowned engineering hardware shops and scrap yards available in the country. This led to the abandonment of the project by the firm. Thus, it can be seen that the non-availability of required engineering materials and components is having an adverse impact on the efficiency and effectiveness of machinery design and manufacturing in the country.

\subsection{Interactions with Machinery Manufacturers}

Effective collaboration and interactions take place 
between machinery manufacturers and engineering inputs suppliers in most technologically advanced countries and elsewhere to ensure that the required engineering inputs are supplied to the manufacturers [15]. Again, specialist material engineers liaise with suppliers, customers and manufactory/development staff to know their needs [16]. As indicated in fig. 7 above, a large majority of the suppliers/dealers as well as the two materials producing firms in the county do not interact with machinery manufacturers to know their needs. Obviously, the lack of effective interaction between the suppliers and machinery manufacturers could lead to a situation where the needed critical engineering materials and components become nonavailable in the country, since suppliers/dealers may not be aware of any lack regarding these inputs.

\subsection{Percentage of Actual Inputs Made Up of Substitutes}

Most renowned machinery manufacturing firms glob- ally aim at producing machines that meet international standards, quality and durability, and therefore, avoid the use of substitute inputs in their machinery manufacturing activities [11]. Whatever the cause, substitution can be a difficult and costly exercise and carries with it a significant risk that the replacement material may not perform adequately in all applications [12]. Simple substitution of one material for another does not usually provide optimum utilization of the new material as investigated by Mahmoud [13].

From the responses on the percentage of actual inputs made up of substitutes given in section three of this paper, a large majority of the machinery designers and manufacturers indicated that their actual inputs consist of at least between $50 \%$ to $100 \%$ substitute materials and components. Moreover, majority of the machinery manufacturers said in an informal interview that they 'sometimes' alter their design specifications to accommodate the available substitute engineering materials and components. Undoubtedly, the altering of design specifications leading to a massive usage of substitute inputs in the manufacture of machinery may result in reduced machinery functionality and durability. The products may fall short of international standards and cannot be exported.

\section{Conclusion}

Machinery design and manufacturing help not only to add value to a country's natural resources, but also serve as a catalyst to facility economic growth and development. Manufacturing activity, however, strives on uninterrupted supply of required engineering inputs. Currently, the critical engineering inputs are brought into the country from outside sources with their qualities not determined. Engineering products manufacturers in the country such as 'Gratis Foundation', 'Sis Engineering Limited', 'Homeku Engineering Limited', 'Agbemskod Engineering Limited' and so on tend to experience undue delays most of the times in their manufacturing activities as a result of non- availability of the required engineering inputs. This affects manufacturing effi- ciency and effectiveness greatly in the country. To this end, The government, banks as well as other corporate organizations should assist to expand and resource the few existing engineering materials producing firms as well as establish new ones in the country to help produce more of the required engineering inputs locally and by so doing create jobs. The Ghana Institution of Engineers, and The Ghana Standards Board should organize in-service training and workshops regularly for the suppliers/dealers to enable them upgrade and update their technical competencies and engineering literacy levels. Again, there should be constant and regular interactions between machinery manufacturers and suppliers/dealers to enable the suppliers to be informed about the required engineering inputs so they can make them readily available in the country. Moreover, engineering graduates from the country's training institutions, particularly the universities and polytechnics, should be encouraged to go into the design and manufacture of machinery as well as the supply of engineering inputs to ensure availability and correct specification of the inputs.

\section{References}

[1] Project Syndicate, 2014, Factsheet: The Real Raw Materials of Wealth. Available at http://www.projectsyndicate.org/commentary/ricardo-hausmann-advises-poorcountries-not-to-focus-solely-on-adding-value-to-naturalresource-exports. [Accessed on 15th July, 2014].

[2] The world Factbook, 2014, Factsheet: Central Intelligence Agency [Online]. Available at http://www.cia.gov/library/publications/the-world-facebook/fields/2111.html. [Accessed on 20th August, 2014].

[3] J. Powell, "Technology and Enterprise Development Project Report", 1995.

[4] Industrial Areas in Ghana, 2014, Factsheet: Map for Industrial Areas in Ghana [Online]. Available at https:www.google.com.gh. [Accessed on 20th June, 2014].

[5] AKSTeel, 2011, Factsheet: Supplier Requirements Manual [Online]. Available at http:www.aksteel.com/pdf/AKSSupplier-Reqmts-Manual-2011.pdf. [Accessed on June, 2014].

[6] Code of Ethics for Engineers, 2014, Factsheet: National Soc- iety of Professional Engineers [Online]. Available at http:w- ww.nspe.org/resources/ethics/code-ethics. [Accessed on May, 2014].

[7] Key to Metals, 2005, Factsheet: Steel. [Online]. Available at http://www.steel.Keytometals.com. [Accessed on 30th July, 2014].

[8] Materials Science, 2014, Factsheet: Wikipedia, The Free Encyclopedia. [Online]. Available at http://en.wikipedia.org/wiki/materials-science. [Accessed on 15th July, 2014].

[9] C. Millwright, "Mechanical Engineering Manual for Instruction", Ministry of Advanced Education, 1990, pp. 143-150. 
[10] Misumi, 2014, Factsheet: The Crucial Role of Material Selection. [Online]. Available at http://www.us.misumiec.com $/ \mathrm{maker} / \mathrm{mis}-$ umi $/ \mathrm{mech} / \mathrm{tech} / \mathrm{materialselection.}$ [Accessed on 20th June, 2-014].

[11] Rino Mechanical Components Incorporated, 2005, Factsheet: Gear Boxes. [Online]. Available at http://www.rinomechanical.com. [Accessed on 30th April, 2014].

[12] Chapter 10-Materials Substitution, 2014, Factsheet: Materials Selection for Engineering Design [Online]. Available at http://www.facultyl.aucegypt.edu/farag/presentations/chapter10.pdf. [Accessed on 15th July, 2014].

[13] M. Farag, 2014, Factsheet: Materials and Process Sel-ection for Engineering Design. Available at
htpp://www.goodreads.com/author/show/1646362.Mahmou d M. [Accessed on 20th may, 2014].

[14] G. Murray, "Handbook of Materials Selection for Engineering Applications”, CRC Press, 1997, PP. 11-12.

[15] Targetjobs, 2014, Factsheet: Materials Engineer: Job Description. Available at http://targetjobs.co.uk/careersadvice/job-descriptions/276077-materials-engineer-job description. [Accessed on 20th June, 2014].

[16] R.S. Khurmi and J.k. Gupta, "Textbook of Mechanical Design", 5th Edition, McGraw Hill Publications 1989, pp. 2531 .

[17] Buck and Hickman Ltd. "General Catalogue of Tools and Supplies", John Bellows Ltd., 1991, pp.810-820. 